done a complete post-take ward round, and returned to pick them up as they finished a leisurely cup of coffee. The difference is that I know that if I forgo that ward round and later discover that something is amiss I will have to spend the whole evening there sorting it out, instead of doing whatever I had planned for what we consultants laughingly call "off duty."

The candidates also need to see some of the professional satisfaction and the heartache that each day brings. I also suggest to them that, to make their decision to apply to medical school, they should spend one or two days with a hospital consultant, such as myself, perhaps a week with their general practitioner, and a fortnight on the "executive side" actually doing something with the sick, such as working in an old folks' home or a handicapped children's home. If, after all of this, they still feel comfortable with this environment, are not revolted, and are not physically or mentally overtired then they have the potential to go into medicine, qualify, and find a fulfilling niche.

I am enormously grateful to my junior medical staff; our ward, theatre, and endoscopy staff; and our administrators for their enthusiastic and continuing support for this project.

\title{
In defence of eponyms
}

\section{Wright}

Academics commonly deride eponyms as vehemently as they insist on unpronounceable generic names for drugs instead of euphoneous trade names on the basis of cost. The aetiology of the use of eponyms is multifactorial, and not all the reasons for their use are despicable. Let me enter the lists in their defence by providing reasons for their use.

\section{Hiding distressing aspects of a disease}

Mongolism may have been a vivid description of the patient suffering from Down's syndrome, but how much more humane is the eponym. It also avoids suggestions of racial prejudice. Likewise, Hurler's syndrome is preferable to gargoylism.

In emphasising the term Hansen's disease for leprosy' the late Dr Stanley Brown minimised the use of "leper" with all its destructive and ostracising associations. When, in 1981, the British Medical Association invited me to lecture at their annual conference in San Diego on aspects of rehabilitation, it selected the catchy title, "Disability: the new leprosy." Imagine my dismay on returning to Leeds to read the description of my visit in the local newspaper under the headline "Leeds professor says disabled people are lepers." No self respecting editor would have used the precious front page to exclaim, "Leeds professor says disabled have Hansen's disease."

An eponym can, moreover, give dignity to a sufferer. Who would wish to be called an "india rubber man" when he can proudly announce to his friends he has Ehlers-Danlos syndrome? One of my senior registrars commented that she had been glad, in younger years, that she had Perthe's disease, rather than "avascular necrosis of the hip occurring in small (stunted) children of low social class."

\section{Crediting the origin of a new understanding}

This is the usual reason for using an eponym, and is entirely appropriate. The pleasantly sounding von Willebrand deserves to have his name attached to the usually mild bleeding disorder, the fundamental lesion of which is an insufficiency of or a defect in his factora protein that promotes platelet adhesion. An eponym is preferable also to an acronym such as SARA (sexually acquired reactive arthritis), which attaches a

\section{Rheumatology and}

Rehabilitation Research Unit, University of Leeds, Leeds LS2 9NZ

V Wright, FRCP, $A R C$ professor of rheumatology

$B M \mathcal{J} 1991 ; 303: 1600-2$

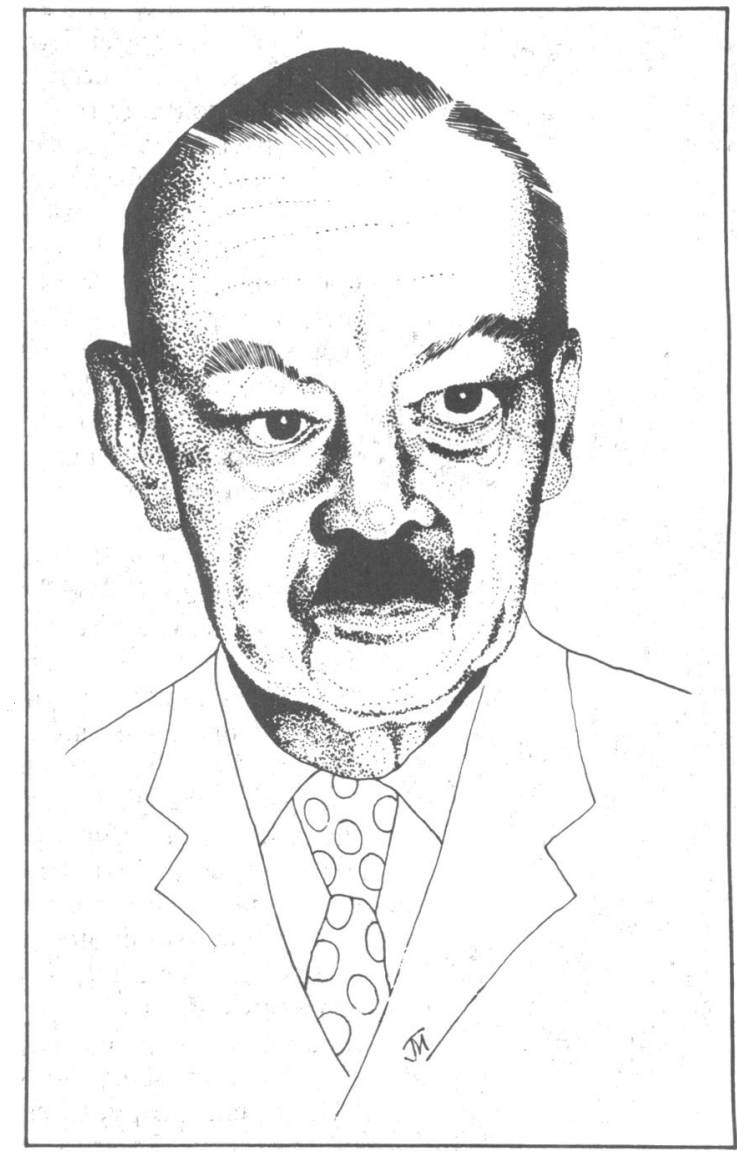

Hans Reiter (1881-1916)

their observations in marvellously descriptive phrases. The discussion by George Frederic Still (while a medical registrar at Great Ormond Street Hospital) of the spectrum of conditions that comprise juvenile chronic arthritis is masterly. ${ }^{3}$ Several years elapsed before rheumatologists woke up to the fact that these children did not have juvenile rheumatoid arthritis but a cluster of diseases, as Still had indicated. The descriptions of Felty and of Whipple-both from the Johns Hopkins Hospital, Baltimore-of their respective syndromes cannot be bettered..$^{45}$

As investigators have often found, knowledge of a few patients well described originally is usually little extended by vast surveys in later years. Moreover, the original author's insights were often profound. Reiter's syndrome is defined as the triad of non-specific urethritis, conjunctivitis, and arthritis. Hans Reiter himself described the case of a cavalry officer serving 
on the Balkan front who developed an acute dysenteric illness followed by arthritis, urethritis, and conjunctivitis. ${ }^{6}$ Later, studies in Scandinavia and Belgium made us appreciate the importance of the bowel in a search for clues about the cause of reactive arthritis and other seronegative spondarthritides. ${ }^{78}$

\section{A basis for argument about precedence}

Vigorous correspondence has often ensued about who first described a syndrome. By common usage Reiter has secured a place in medical history with his eponymous syndrome-but what about Pierre and Forest, who as long ago as 1507 described a patient with arthritis of the knee in association with urethritis, and Martinière, who recognised arthritis as a complication of urethritis in 1664? Moreover, in 1818 Sir Benjamin Brodie described the syndrome. ${ }^{10}$ The debate over precedence makes a good opening to the chapter on the subject in the classic British textbook of the rheumatic diseases. ${ }^{11}$

The dissension becomes sharp when national honour is at stake. Whose name should be attached to ankylosing spondylitis? Is it the Russian, Vladimir Bechterev, ${ }^{12}$ or the German, Adolf von Strümpell, ${ }^{13}$ or the Frenchman, Pierre Marie ${ }^{14}$ More can be written on the spelling of the names-alternatives to Bechterev have been Bechterew, Bechtereff, and Bekhterew. ${ }^{15}$

\section{Impressing general practitioners}

Once general practitioners were likely to say, "A bilateral nephrectomy was performed" instead of "Both kidneys were removed." Now they are hoist by a similar but more sophisticated petard, from which they will not be readily released by the standard medical dictionary, as they are bombarded with terms such as Kartagener's syndrome and Takayasu's disease. A slim volume by Huskisson and Hart lists over 150 rheumatic diseases, of which one in seven is eponymous. ${ }^{16}$ Indeed, who wishes to talk about O'nyong-nyong or Acanthocheilonema perstans disease when an eponym would have sufficed? Some specialties make a practice of turning straightforward English

Illustrations by Drf M H Moll first appeared in "Seronegative polyarthritis"'s

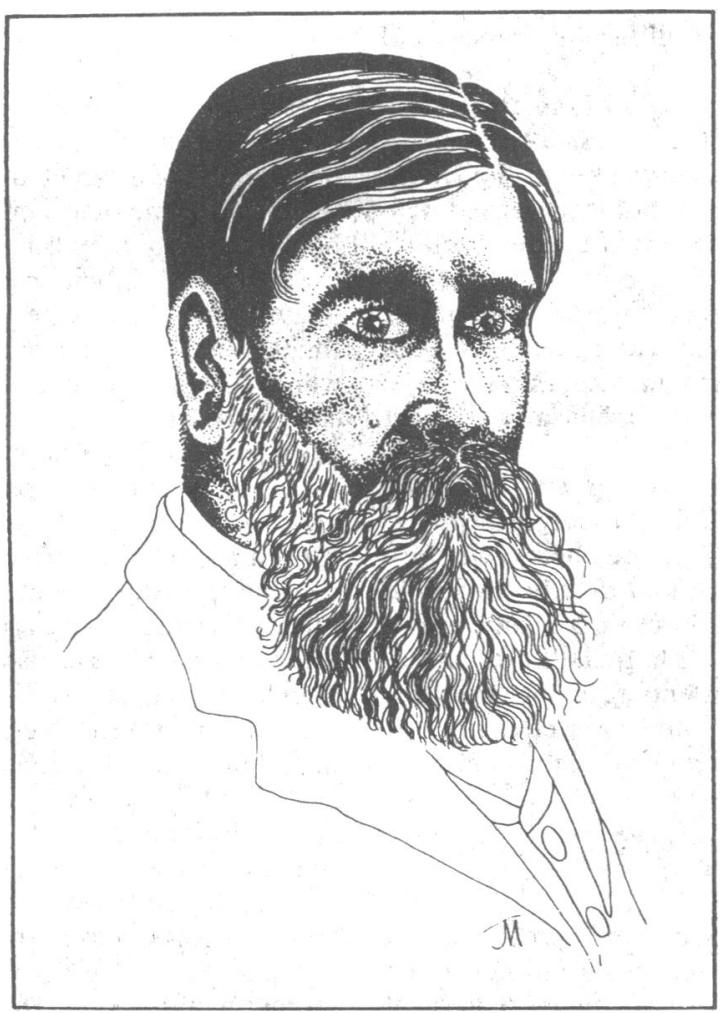

Vladimir Michailovitch Bechterev (1857-1927)

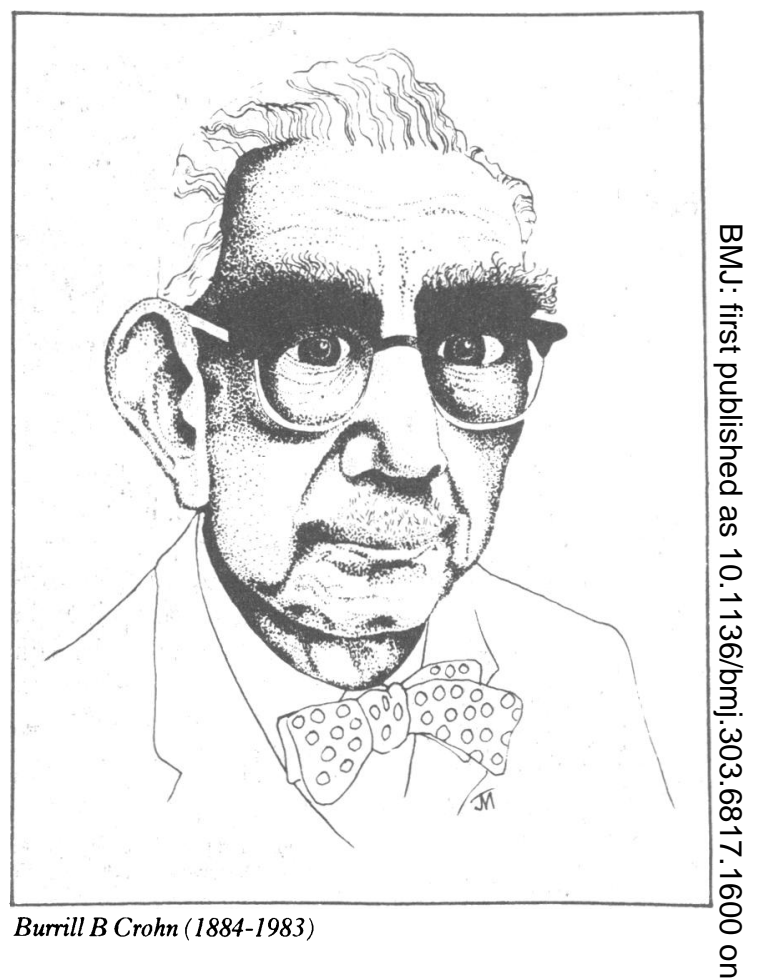

descriptions of the signs into Latin, and they call that a diagnosis. To avoid this, eponyms have as much to $\vec{\nabla}$ commend them.

\section{Avoiding a display of ignorance}

Crohn's disease is a perfectly satisfactory title for the $\vec{\theta}$ granulomatous gastrointestinal disease it indicates. ${ }^{17}$ Authors who insisted on calling it "regional ileitis" must now explain why lesions have been found in the? stomach and the colon. Those of us who stood by the name of Burrill B Crohn have nothing to fear from fresh pathological discoveries.

Those who called Bechterev's disease rheumatoid $\stackrel{\mathbb{\Omega}}{-}$ spondylitis would have been spared many blushes had $\overline{\bar{B}}$ they used the eponym instead, as the disease is evidently not a variant of rheumatoid arthritis clinically, genetically, serologically, radiologically, pathologically, or in its response to treatment. Furthermore, what do you make of a disease called ankylosing spondylitis when the patient has sacroiliac joints that are not fused (nor ever likely to be), although they show sacroiliitis, and when the spine shows no radio-o logical changes of spondylitis (nor is likely to do so)so that the patient is not ankylosing nor shows응 spondylitis?

Enabling examiners for postgraduate qualifications to display their erudition

How reassuring to candidates when the examiner asks if they know who Wegener was. Should a candidate by some quirk of fate know the answer, that will be most impressive. On the other hand, if the candidate does not the examiner will provide enlightenment with a biographical sketch of the man. (Few women have their names attached to syndromes, $\overrightarrow{\mathbb{D}}$ although Dorothy Reed gave her name to a cell, and the $\frac{\text { ? }}{\mathbb{D}}$ Barr of Epstein-Barr attached her name to the man and 2 the virus.) Thereby valuable viva time, in which lack of knowledge could be exposed, will have been used. The? examiner, being a just man, will not deduct marks foro ignorance of things that have little relevance to aㅊ patient's welfare, and which a candidate could not be? expected to know. A warm, self congratulatory glow will so pervade the examiner that the rest of the questions will be softened accordingly. 
Such an inquiry also gives the teacher the chance to make insulting remarks about the person in question. The mention of Dupuytren will remind him to say that Dupuytren thought the contracture he described in coopers resulted from the pressure of the barrels on their hands. We now know that the contents of the barrels were likely to be more damaging than the casks. It is so much more effective to personalise one's insults, and if they can be directed to a defunct figure, likelihood of an action for slander is vastly diminished.

\section{Conclusions}

Purists may shun eponyms, but practical doctors appreciate their value. Those who use them need have no guilt complex, but rather a self righteous glow. For good, bad, and indifferent reasons eponyms will continue to be used and indeed should be. Clinicians, therefore, should be diligent in describing carefully new syndromes - their name may become attached to the symptom complex and thus they may be remembered by posterity.

1 Thompson P. Mister leprosy. Hodder and Stoughton, London: 1980. 2 Keat AC, Maini RG, Pegrum DG, Scott JT. The clinical features and HLA associations of reactive arthritis associated with non-gonococcal urethritis. Quart f Med 1979;48:323-42.

3 Still GF. On a form of chronic joint disease in children. Medico Chir Trans 1897;80:47-59.

4 Felty AR. Chronic arthritis in the adult, associated with splenomegaly and leucopenia: a report of five cases of an unusual clinical syndrome. Johns Hopkins Med Bull 1924;35:16.

5 Whipple GH. A hitherto undescribed disease characterised anatomically by deposits of fat and fatty acids in the intestinal and mesenteric lymphatic tissues. Bull fohns Hopkins Hosp 1907;18:382-9.

6 Reiter H. Über eine bisher unerkannte Spirochateninfection (Spirochaetosis arthritica). Dtsch Med Wchschr 1916;42:1535-8.

7 Paronen I. Reiter's disease: a study of 344 cases observed in Finland. Acta Med Scand 1948;131(suppl 212):1-123.

8 Mielants $\mathrm{H}$, Vey EM. Clinical and radiographic features of Reiter's syndrome in inflammatory bowel disease related to arthritis. Curr Opin Rheum 1990;2:570-6.

9 Sharp JT. Reiter's syndrome (reactive arthritis). In: Hollander JL, McCarthy DJ, eds. Arthritis and allied conditions. 8th ed. Philadelphia: Lea and Febiger, 1229-41.

10 Brodie BC. Pathological and surgical observations on diseases of the joints. London: Longman, 1818:54.

11 Scott JT, ed. Copeman's textbook of the rheumatic diseases. 6th ed. Edinburgh: Churchill Livingstone, 1986:787.

12 Bechterev VM. Steifigkeit der Wirbelsaule und ihre Verkrummung als besondere Erkrankungsform. Neurologisches Centralblatt 1893;12:426.

13 Strumpel A. Bermerkungen über die chronische ankylosirende entzudung der Wirbelsaule und der Hauftgelenke. Deutsche Zeitschrift fur Nervenhellkunde, 1897;11:338.

14 Marie P. Sur la spondylose rhizomelique. Reoue de Medicine 1898;18:285. 15 Wright V, Moll JMH. Seronegative polyarthritis. Amsterdam: North Holland Publishing, 1976.

16 Huskisson EC, Hart FD. Foint disease: all the arthropathies. Bristol: John Wright, 1973.

17 Crohn BB, Coinsburg G, Oppenheimer D. Regional ileitis - a pathological and clinical entity. JAMA 1932;99:1323-8.

\title{
Microbial flora on doctors' white coats
}

\author{
Derek Wong, K Nye, Pat Hollis
}

\begin{abstract}
Objective-To determine the level and type of microbial contamination present on the white coats of doctors in order to assess the risk of transmission of pathogenic micro-organisms by this route in a hospital setting.
\end{abstract}

Design-Cross sectional survey of the bacterial contamination of white coats in a general hospital.

Setting-East Birmingham Hospital, an urban general hospital with 800 beds.

Subjects -100 doctors of different grades and specialties.

Results - The cuffs and pockets of the coats were the most highly contaminated areas. The level of bacterial contamination did not vary with the length of time a coat had been in use, but it increased with the degree of usage by the individual doctor. Staphylococcus aureus was isolated from a quarter of the coats examined, more commonly from those belonging to doctors in surgical specialties than medical specialties. Pathogenic Gram negative bacilli and other pathogenic bacteria were not isolated.

Conclusions -White coats are a potential source of cross infection, especially in surgical areas. Scrupulous hand washing should be observed before and after attending patients and it may be advisable to remove the white coat and put on a plastic apron before examining wounds. There is little microbiological reason for recommending a more frequent change of white coat than once a week, nor for excluding the wearing of white coats in non-clinical areas.

\section{Introduction}

Wearing a white coat is an accepted part of medical practice. The actual use of white coats and how often they are changed varies greatly among individual doctors and their specialties. There has always been some concern that white coats, like nurses' uniforms and other hospital garments, may actually play a part in transmitting pathogenic bacteria in a hospital setting. ${ }^{1-5}$ There has also been controversy over whether doctors should be barred from wearing white coats in areas such as staff canteens, tea rooms, and $\Phi$ libraries. In this study we examined the white coats $\overrightarrow{\vec{O}}$ of doctors from East Birmingham Hospital for the presence of bacteria and in particular for potentially pathogenic bacteria.

\section{Methods}

One hundred doctors of different grades and specialties from East Birmingham Hospital participated in the study. The time that their white coat had been in use, how frequently they usually changed their coats, and the actual use of their coats were determined by direct questioning. The usage of a white coat was defined $\mathcal{N}$ roughly as the percentage of time the coat was worn $I$ while the doctor was on duty. In addition, the cleanliness of the coat in appearance was subjectively $N$ assessed by a single observer. Of the 100 doctors, $45 \mathrm{~N}$ were house officers or senior house officers, 26 were registrars or senior registrars, and 29 were from consultant or other grades. A total of 51 worked in

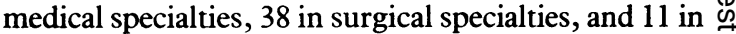
other specialties such as accident and emergency. Ten clean unused white coats were taken from the hospital $\bar{\partial}$ laundry as controls.

Impressions were taken from three different areas of $\mathbb{\Phi}$ the white coat using $25 \mathrm{~cm}^{2}$ contact plates containing $5 \%$ horse blood agar. The sites sampled were the cuff and the lower front pocket of the coat, where microbial 8 contamination was thought to be greatest as these are the most heavily used areas on a white coat.$^{1-4} \mathrm{~A}$ further $\hat{0}^{\circ}$ sample was taken from the back of the coat at the level ? of the lower part of the scapula to assess background contamination. After 18 hours' incubation in air at $37^{\circ} \mathrm{C}$ the plates were examined for the total microbial 